\title{
Study on preparation and performance of polyacrylate emulsion used as wood assembly adhesive
}

\author{
Xiaoyue Liu ${ }^{1, a}$, Chao Zhu ${ }^{1, b}$, Qing Xiang ${ }^{1, c}$ and Liming Dong ${ }^{1, d *}$ \\ ${ }^{1}$ School of Chemical Engineering, Xuzhou Institute of Technology, Xuzhou, 221111, China \\ a18052125714@163.com, b18361271096@163.com,, ${ }^{\mathrm{C}} 15152466547 @ 163 . c o m,{ }^{\mathrm{d}}$ polymerdlm@163. \\ com
}

Corresponding Author: Liming Dong

Keywords: Polyacrylate emulsion, Wood assembly adhesive, Emulsion polymerization

\begin{abstract}
A kind of adhesive for wood assembly, which can be used in normal temperature and pressure and shown better mechanical properties, was successfully prepared by emulsion polymerization Methyl methacrylate (MMA) and Butyl acrylate (BA) as monomers, and the polyaryl methene isocyanate (PAPI) as cross-linking agent. The structure of the polymers and emulsion was characterized by FT-IR, GPC and DSC. The effect of prescription composition, viscosity, solid content and crosslink agent content were studied by mechanical property test on the properties of adhesive. The results show that wood assembled adhesive exhibits excellent adhesive strength, the good strength of $14.8 \mathrm{MPa}$ could be obtained with 48 hours of maintain at normal temperature and pressure.
\end{abstract}

\section{Introduction}

Polyacrylate (PA) emulsion was the product of emulsion polymerization with acrylic and methylacrylate as main monomers. It has been widely used in the following aspects such as coating for film forming, adhesive, daily chemical industry, chemical power sources, functional film, medical polymers, nano material and water treatment for environmental requirement, for it is easy to design molecular structure and the performance of synthesis technology, excellent property, low price and good stability[1,2]. PA emulsion is an environmentally adhesive owning no-formaldehyde and using conveniently and safely. When it was used with polyfunctional compound of isocyanate as cross-linking agent, outstanding advantages of adhesive include cured at room temperature, water resistance, excellent heat resistance and anti-aging properties, while reasonable price, and widely used in the production of small cross section construction timber, furniture puzzle, doors and windows, plywood, decorative board widely[3-5].

In order to obtain the target adhesive strength and effectiveness, adhesives often use hot-pressing process. It was contributed to produce more chemical cross-linking structure and more the contact area of the combined interface to improve the adhesive strength [6]. However, the poor conditions of pressure value and direction exist widely in the actual furniture assembly production process $[7,8]$, which put forward a higher requirement to the performance of adhesive. The adhesive, which main agent was obtained by in situ emulsion polymerization with MMA and BA, PVA as thickener, heavy calcium as filler and PAPI as cross-linking agent, could realize high strength assembly and adhesive at normal temperature and pressure.

\section{Experimental}

\subsection{Materials.}

PVA(BP-24, BP-17)was obtained from Taiwan Changchun Co., Ltd.; PAPI(PM-400) as crosslink agents was obtained from Yantai Wanhua Polyurethane Co., Ltd.; MMA, BA, sodium dodecyl 
benzene sulfonate(SDBS), polyoxyethylene octyl phenyl ether(OP-10), potassium persulfate(KPS), sodium bicarbonate $\left(\mathrm{NaHCO}_{3}\right)$ and heavy calcium were all chemically pure and gifted by the QiYanli paint Co., Ltd; The monomers was used after process of vacuum distillation to remove polymerization inhibitor; KPS and $\mathrm{NaHCO}_{3}$ were used after the twice-recrystallized.

\subsection{Preparation of adhesive.}

The proper amount of Water, heavy calcium, $\mathrm{NaHCO}_{3}$, two kinds of emulsifier (SDBS and OP-10) and PVA were charged into a three-necked round-bottom flask equipped with a condenser, nitrogen inlet/outlet in turn. The mixture was constantly stirred at $80^{\circ} \mathrm{C}$ until PVA completely soluble and heavy calcium dispersing well. A certain proportion of the two kinds of monomers and residual emulsifier were developed for pre-emulsion, and then little emulsion mixture and initiator solution were added into flask for reaction. After 30min, adding emulsion mixture step by step and supplement adding initiator solution in batch, then insulation to react for 1 hour after pre-emulsion dripping off. Then the reaction system will be heated up to $95^{\circ} \mathrm{C}$ and constant temperature for $30 \mathrm{~min}$ to make monomer response fully, Cooled to $40^{\circ} \mathrm{C}$, control system $\mathrm{pH}$ value for neutral, cooled filter discharging and got adhesive main agent finally. The assembly adhesives can be obtain after crosslink agent is mixed with the main stirred uniformly.

\subsection{Performance Testing.}

Emulsion polymer was purificated before testing according to method which the sample was demulsificated, dissolved in chloroform, settled in ethanol to get white flocculent material and then placed in vacuum oven at $50^{\circ} \mathrm{C}$ for $24 \mathrm{~h}$. Fourier transform infrared (FTIR) spectra were recorded using the $\mathrm{KBr}$ pellet method on a ALPHA spectrophotometer. Gel permeation chromatography (GPC) was carried out using a PL-GPC50 instrument with $\mathrm{CHCl} 3$ as mobile phase and the values were calibrated versus polystyrene standards. The glass transition temperature ( $\mathrm{Tg}$ ) was determined with a TA Q20 differential scanning calorimetry (DSC) in flowing nitrogen at a heating rate of $15^{\circ} \mathrm{C} / \mathrm{min}^{-1}$ from -65 to $180^{\circ} \mathrm{C}$. Thermal history was eliminated by heating and cooling. Emulsion was filtered through 100 mesh screen after polymerization. Flocculates were weighed after washing and drying to constant quality in $100^{\circ} \mathrm{C}$. The Gel Content can be calculated the percentage of flocculates in total monomers. Compression shear strength was tested referencing the standard of HG/T 2727-2010, using specifications for $30 \mathrm{~mm} \times 25 \mathrm{~mm} \times 10 \mathrm{~mm}$ as birch specimens.

\section{Results and discussions}

\subsection{Polymer Emulsion Synthesis.}

The FTIR spectra of polymers were as shown in Fig 1. The spectral curve of P1 was corresponded to the homopolymer of MMA, There are two the absorption band at $1618 \mathrm{~cm}^{-1}, 1559 \mathrm{~cm}^{-1}$ corresponding to $\mathrm{C}=\mathrm{O}$ stretching vibration, and $1080 \mathrm{~cm}^{-1}$ corresponding to $\mathrm{C}-\mathrm{C}$ stretching vibration. The spectral curve of $\mathrm{P} 9$ was corresponded to the homopolymer of BA, There are the absorption band at $1734 \mathrm{~cm}^{-1}$ corresponding to $\mathrm{C}=\mathrm{O}$ stretching vibration, and $1160 \mathrm{~cm}^{-1}$ corresponding to $\mathrm{C}-\mathrm{O}$ stretching vibration. The spectral curve of P9 was corresponded to the copolymer spectra with MMA:BA=1:1. Comparing the spectra of homopolymer and copolymer, the FTIR spectra of polymers not only contained the absorption frequency peak of MMA but also the absorption frequency peak of ester group, which showed that the polymer was prepared with the two monomers.

The DSC scanning curves of the polymers was shown in Fig.2. From the figure, we could found that the Tg of PMMA homopolymer (BA,0\%) was $127^{\circ} \mathrm{C}$, which indicated that MMA was a hard monomer. The Tg of polybutyl acrylate homopolymerization (BA, $100 \%$ ) was $-45^{\circ} \mathrm{C}$, which showed that BA was soft monomer. The results of experimental were closed to literature values that the PMMA at $105^{\circ} \mathrm{C}$ and PBA at $-54^{\circ} \mathrm{C}$, which showed that the experimental data were more reliable. The copolymers, which were prepared with hard monomer MMA and soft monomer BA according to mass ratio by copolymerization, were tested by DSC. It has been found experimentally that the Tg of the polymers were between in the Tg of the two homopolymer, and the tendency of Tg decreased with the increase the content of BA, which showed that the results coincided with designing. 


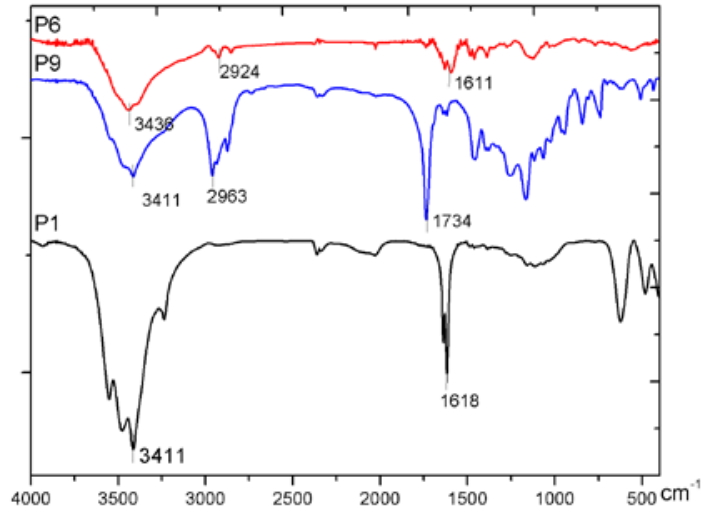

Fig.1 FTIR spectra of polymers

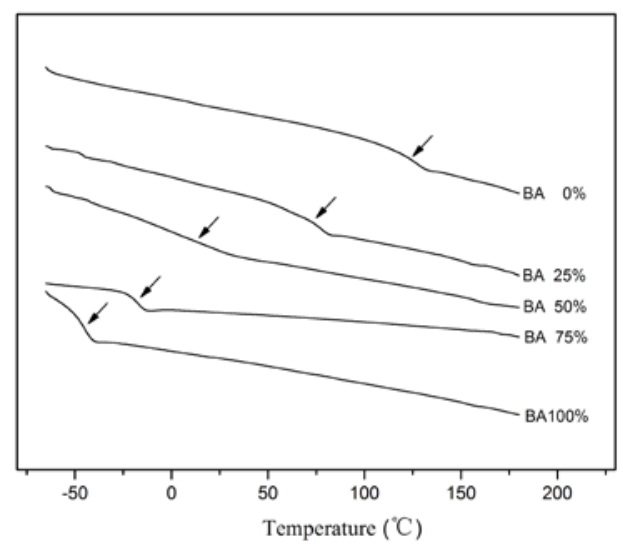

Fig.2 DSC scanning curves of the polymers

Relative high molecular-weight polymers were readily obtained by emulsion polymerization. GPC analysis of the resulting polymers revealed that they had averaged number molecular weights over $2.5 \times 10^{5}$ and polydispersities in the range of 1.1 2.05 (Table 1), respectively, which illustrated that the production was reliable and well performance. The gel content was tested in order to measure the stability of emulsion production. It has been found experimentally that the polymer was more ideal for less gel content when the content of monomer reached $40 \%$ emulsion quantity. Gel content values were less when the content of hard monomer MMA was higher, which illustrated that the reaction was stable and the yield of polymerization was higher. However, gel content tended to increase significantly when BA content was more than over $50 \%$ quantity of all monomer, which illustrated that the polymer contained more flexible composition, the emulsion particle diameter was easier to occur adhesion and product gel structure mass.

Table 1 Properties of Polymers

\begin{tabular}{ccccccc}
\hline $\begin{array}{c}\text { Sample } \\
\text { code }\end{array}$ & $\begin{array}{c}\text { BA Content } \\
(\%)\end{array}$ & $\begin{array}{c}\overline{\mathrm{M}}_{\mathrm{n}} \\
\left(\times 10^{4}\right. \\
(\%\end{array}$ & $\begin{array}{c}\overline{\mathrm{M}}_{\mathrm{w}} \\
\left(\times 10^{4}\right.\end{array}$ & PDI & $\begin{array}{c}\text { Gel Content } \\
(\%)\end{array}$ & $\begin{array}{c}\text { Shear strength } \\
(\mathrm{MPa})\end{array}$ \\
\hline 1 & 0 & 31.34 & 56.38 & 1.80 & 1.31 & 6.17 \\
2 & 12.5 & 45.96 & 50.93 & 1.11 & 1.36 & 6.95 \\
3 & 25 & 41.43 & 53.24 & 1.28 & 1.25 & 7.49 \\
4 & 37.5 & 39.49 & 56.07 & 1.42 & 1.82 & 10.41 \\
5 & 50 & 46.88 & 60.67 & 1.29 & 1.63 & 11.88 \\
6 & 62.5 & 60.50 & 67.57 & 1.12 & 2.56 & 14.80 \\
7 & 75 & 43.13 & 60.28 & 1.40 & 3.41 & 13.39 \\
8 & 87.5 & 25.4 & 41.94 & 1.65 & 5.69 & 9.49 \\
9 & 100 & 16.29 & 33.41 & 2.05 & 8.6 & 7.10 \\
\hline
\end{tabular}

\subsection{The effects of formulations on adhesive properties.}

The hard monomer of MMA was chosen as to provide the strength and hardness, and the soft monomer of BA was chosen as to provide the softness and adhesion in this copolymerization emulsion formula. The shear strength test results with different content of emulsion BA were as shown in table 1. It has been found experimentally that the shear strength appeared the trend of first increase then decrease with the increase of content of BA, and reached maximum (14.80MPa), when it was $62.5 \%$. The experiment results reached the standard test requirements of HG/T 2727-2010. The monomer ratio of polymer will affect Tg of copolymer. If the Tg value was too high, adhesive film was hard and brittle for the higher film-forming temperature, and which will affected the strength of adhesive connect; if the Tg value was too low, the adhesive film was softer, which will also affect the strength of adhesive connect.

The practical invasive of adhesive is closely related to viscosity or fluidity, however, the viscosity of main agent is closely related to the content of PVA dissolved in water. The viscosity prepared by 
experiment can be adjusted by the content of different components and grade of PVA. The effect of the main agent viscosity to adhesion property was shown in Fig 3. The results show that the shear strength was increase first and then decrease with the viscosity increasing. For the reason of good mobility, the adhesive was easy to excessive glue and the effective constituent of unit surface was little, so the strength was poor. For the reason of bad mobility, the adhesive was difficult to infiltrate surface, so the strength was also poor. When viscosity was $25000 \mathrm{mPa} . \mathrm{s}$ in PVA viscosity curve, the highest value was 14.8MPa.

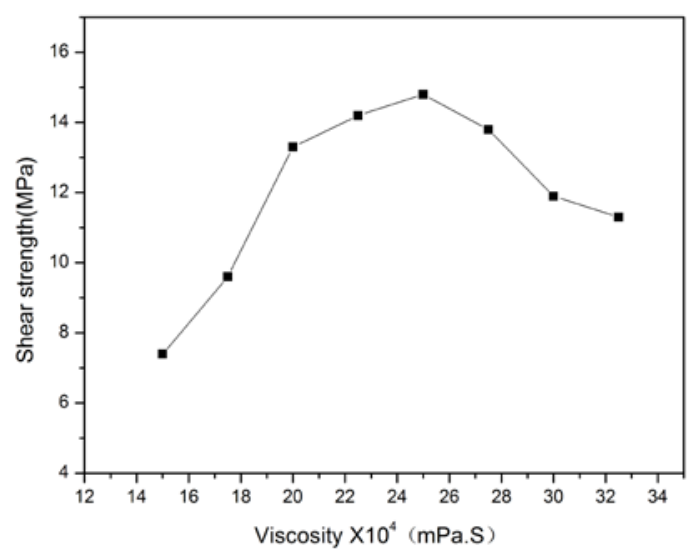

Fig.3 Effect of main agent viscosity on properties of adhesive

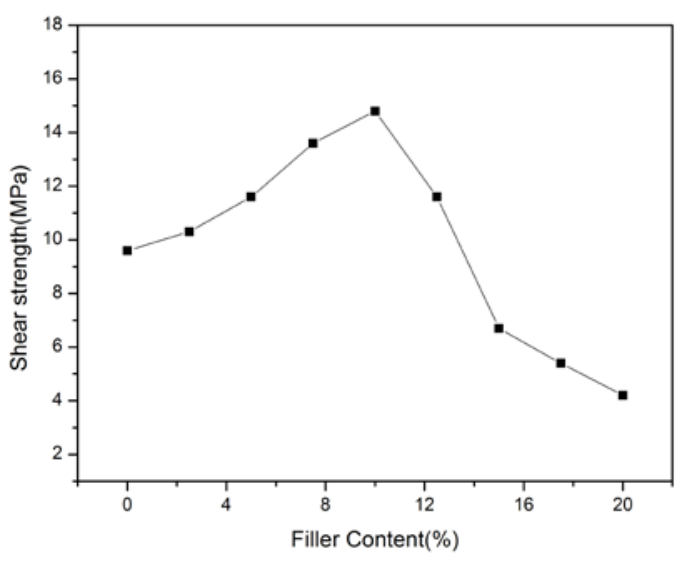

Fig.4 Effect of filler content on properties of adhesive

The impact of the filler content on the adhesive properties was shown in Fig. 4.The results show that the shear strength presents the tendency of reduction afterwards with the increase of light calcium. While heavy calcium appears sharp drop after the highest value 14.8MPa occurs at the content of $10 \%$. The dosage of filler had direct effect to the level of solid content because the content of monomer in emulsion was set to $40 \%$. Adopting in-situ polymerization, the homogeneous dispersion of filler in emulsion system was higher because solid particles could be effectively isolated by polymer, which could improve solid content effectively. In initial stage, with the increase of solid content, the proportion of the polymer component adds, as well as effective adhesive components are more and the bonding effect increases significantly. In the late stage, the filler proportion increases while the components of effective adhesive and bonding effect decrease.

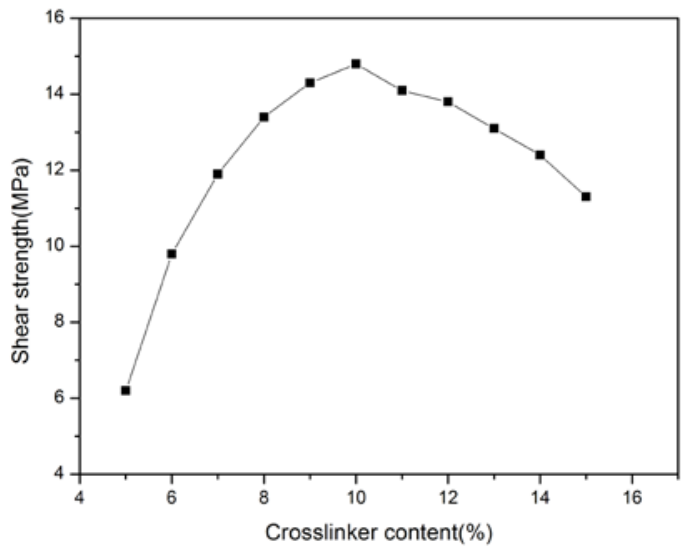

Fig.5 Impacts on the adhesive properties of crosslink agent content

The impacts on the adhesive properties of crosslink agent content is shown in Fig 5, its content is the ratio of the crosslink agent and the main agent. The results show that the shear strength presents the tendency of increase first and reduction afterwards with the increase of crosslink agent content. Complete cross-linked network can not be formed as the content of crosslink agent is less, along with the less chemical reactions between crosslink agent and wood interface and the lower shear strength. 
With the crosslink agent increasing, the intensity is increased significantly. When the crosslink agent content was $10 \%$, shear strength of the adhesive reached maximum $14.8 \mathrm{MPa}$. When excessive cross-linking agent was used, the viscosity of adhesives in its useful life will increase along with the weakened adhesive fluidity and infiltrating so as to decrease the strength. Contrary to the optimum amount of crosslink agent was 15\% under the conditions of heating and pressurizing in the literature, crosslink agent content used in present formulation was less, which may be related to the slower crosslink reaction rate.

\section{Summary}

(1) A novel class of PA emulsion with relative high molecular-weight and narrowly polydispersities were successfully synthesized by copolymerization of MMA and BA. The Tg of copolymer decrease with the increase of BA content.

(2) The performance of adhesive is optimal, when the of BA is 62.5\% (monomer content), filler content of $10 \%$, PAPI $=10 \%$ (host-based quality) and viscosity $25000 \mathrm{mPa}$.s. The adhesive is very suitable for manufacturing and assembly of wooden furniture that an ideal wood adhesive production, which owns excellent weather resistance and adhesive strength can be achieved 14.8 MPa by curing 48 hours under normal temperature and pressure.

\section{References}

[1]. Lovell, Peter A., and Mohamed S. El-Aasser, eds. Emulsion polymerization and emulsion polymers. Wiley, 1997.

[2]. X.Y. Zhang, W.P. Tu, H.Q. Cheng, Research progress of acrylate copolymerical emulsion[J]. Chemical industry and engineering, 2003, 20(2): 84-88.

[3]. C. Cao, L. Lin, Study on acrylic copolymer emulsion for wood adhesives[J]. Adhesion, 2011, 32(3): 58-61.

[4]. Zh. Wu, Y. Xiang, L.T. Zhang, etc. Study on preparation and properties of aqueous wood adhesive[J].China adhesives, 2013, 21(12): 45-48.

[5]. X. Li, Y.D. Shen, X.R. Li, etc. Preparation and characterization of acrylics resin-silicasol /isocyanate wood adhesive without formaldehyde[J].Functional materials, 2011, 42(9): 1639-1641.

[6]. J. Zhang, J.Y. Gu, Y.H. Zhang, etc. Study on characteristic of API curing reaction process [J]. China adhesives, 2009, 18(2): 1-4.

[7]. K.D. Gao, Preparation of New One Component Adhesive for Furniture Assembly[J]. Forestry Science and Technology, 2009 (3): 53-55.

[8]. Zh.X. Zhou, X.F. Li, The Influence of the Performance on Threekinds Mortise and Tenon Bevel Joint by Kind of Resin and Pressing Time[J]. Journal of Inner Mongolia Agricultural University, 2008, 29(1): 144-147. 